\title{
Prediction of Distant Metastasis in Head Neck Cancer Patients: Implications for Induction Chemotherapy and Pre-treatment Staging?
}

\author{
Gabriela Studer ${ }^{1}$, Burkhardt Seifert ${ }^{2}$, Christoph Glanzmann ${ }^{1}$
}

\begin{abstract}
Background and Purpose: Intensity modulated radiation therapy (IMRT) combined treatment approaches, surgical and radiodiagnostic advances, respectively, lead to improved local-regional control in head neck cancer (HNC). With increasing local-regional control, distant metastases (DM) become more meaningful. In some trials without concomitant chemotherapy, induction chemotherapy (IC) resulted in an absolute reduction of DM by $\sim 10-15 \%$. In order to define a more efficient selection of patients at risk for DM with respect to IC and M-staging, we analysed our patients treated by contemporary standards.

Patients and Methods: Between 1/2002 to 12/2007, 409 HNC patients were treated with IMRT; 303/409 (74\%) underwent definitive, 106 (26\%) postoperative IMRT. The mean/median follow-up was 23/20 months (3-72). 70\% tolerated 4-7, 9\% 1-3 cycles of simultaneous cisplatin. Treatment followed a prospectively designed protocol. In a previous study with 172 HNC IMRT patients, gross tumor volume (GTV) was found the strongest predictor for local-regional control. In the current study, this criterion has been prospectively tested for DM. Numbers needed to treat were calculated for IC.

Results: DM developed in 28/399 (7\%) patients; 10 presented initially with DM (total 38/409). In 13/28 (46\%), DM remained the only manifestation of disease. GTV was the strongest predictor for DM $(p<0.0001)$ of all tested. Only $4 \%$ of patients with GTV $<70$ cc developed DM, vs. 25\% (18/73) with > 70 cc; only 6 of them $(6 / 73,8 \%)$ developed isolated DM.

Conclusion: GTV was the most significant predictor for DM, that could guide selective pre-treatment M-staging. The subgroup with isolated DM in the high risk group, that could benefit from IC, is small.
\end{abstract}

Key Words: Distant metastasis in HNC · Prognostic factors for distant metastasis · Volumetric staging

Strahlenther Onkol 2008;184:580-5

DOI 10.1007/s00066-008-1951-y

\section{Voraussage der Metastasierungswahrscheinlichkeit bei Patienten mit Kopf-Hals-Tumoren: Implikationen für Induktionschemotherapie und Metastasen-Staging?}

Hintergrund und Ziel: Intensitätsmodulierte Radiotherapie (IMRT) zusammen mit Kombinationstherapien, chirurgischen und radiologischen Fortschritten führte zu Verbesserungen der Lokoregionalkontrolle bei Kopf-Hals-Tumoren (KHT), was Fernmetastasierung (DM) bedeutsamer macht. In einigen Studien ohne simultane Chemotherapie resultierte die Induktionschemotherapie (IC) in einer absoluten DM-Reduktion von 10-15\%. Um DM-Hochrisikopatienten besser selektieren zu können hinsichtlich IC wie auch DM-Staging, analysierten wir unser nach modernem Standard behandeltes IMRT-Kollektiv.

Patienten und Methodik: Von 1/2002 bis 12/2007 wurden 409 KHT-Patienten kurativ IMRT-behandelt: 303/409 (74\%) definitiv, 106 (26\%) postoperativ (mittlere/mediane Verlaufsbeobachtung 23/20 Monate [3-72]). 70\% tolerierten 4-7, 9\% 1-3 simultaner Cisplatin-Zyklen (Table 1). Die Therapie folgte einem prospektiv festgelegten Protokoll. In einer früheren Studie mit 172 KHTPatienten mit definitiver IMRT wurde das "gross tumor volume" (GTV) als signifikantester Prädiktor für die Lokoregionalkontrolle nachgewiesen. In der hier präsentierten Studie wurde dasselbe volumetrische Staging-System getestet hinsichtlich dessen prädiktiven Wert für DM, um eine allfällige IC wie auch die initiale Metastasensuche selektiver auf ein Hochrisikopatientensegment beschränken zu können.

Ergebnisse: DM fanden sich bei 38/409 Patienten bzw. bei 28/399 mit initialem M0-Status (7\%) (Abbildung 1, Tabelle 2); 10 Patienten hatten initial bereits DM. Bei nur 13/28 (46\%) blieben DM die einzige Krankheitsmanifestation. Das GTV erwies sich als signifikantester aller getesteter Metastasenprädiktoren ( $<<0,0001$, Abbildung 2, Tabelle 3); nur 4\% der Patienten mit einem GTV < 70 cc entwickelten DM, vs. 25\% (18/73) mit GTV > 70 cc, von diesen nur 6 mit isolierter DM (6/73, 8\%).

\footnotetext{
${ }^{1}$ Department of Radiation Oncology, University Hospital Zurich, Zurich, Switzerland,

2 Biostatistics Unit ISPM, University of Zurich, Switzerland.
}

Received: August 28, 2008; accepted: September 9, 2008 
Schlussfolgerung: Das GTV war der signifikanteste Voraussageparameter für DM, und könnte als Selektionsparameter für die prätherapeutische DM-Suche dienen. Die Subgruppe mit isolierter Metastasierung in der Hochrisikogruppe, die von einer IC profitieren könnte, ist klein (Tabelle 4).

Schlüsselwörter: Fernmetastasen bei Kopf-Hals-Tumoren · Prognostische Faktoren für Metastasierung · Volumetrisches Staging

\section{Introduction}

Clinical implementation of intensity modulated radiation therapy (IMRT), together with combined treatment approaches in definitive and postoperative treatment settings, surgical and radio-diagnostic advances, respectively, lead to an encouraging improvement of the loco-regional control in head and neck cancer (HNC) during the last years. When compared with the combined treatment arm of two prospective randomized trials from the near past with conventional irradiation (non IMRT), our IMRT cohort [26] showed an improvement of 3-year local-regional and overall survival rates of $\sim 20 \%$ each ( 70 vs. $\sim 50 \%$, and $\sim 80$ vs. $\sim 60 \%[3,14]$ respectively). This tendency results in a long term survivor population, for which distant metastasis (DM) may become more meaningful [30].

In some trials, induction chemotherapy (IC) has shown to achieve an absolute reduction of DM of 10-15\% [1], [Posner MJ: Educational book ASCO 2006]; IC is recently getting an issue of growing interest. However, its additional risks, mainly of limiting haematological reserves with respect to the following standard concomitant chemo-radiation, should not be underestimated. Risk prediction for DM could help to select and estimate the number of patients, who could benefit of IC.

A second point on which prediction of DM could have an impact on is pre-treatment search for metastasis. DM in HNC is a relatively rare event. Many patients with an a priori low probability for DM have to undergo staging examinations.

Aim of this study was to prospectively identify characteristics of HNC patients at high risk for DM, to achieve a more efficient selection of patients with respect to IC and M-staging.

\section{Patients (Table 1)}

Between 1/2002 and 12/2007, 409 HNC patients have been treated with IMRT for squamous cell carcinoma (SCC, $\mathrm{n}=$ $389)$ or lymphoepithelial carcinoma $(n=20)$ at the Department of Radiation Oncology, University Hospital Zurich (USZ). In 2002, only local-regionally advanced oropharynx tumor patients have been treated with IMRT; since 2003, all HNC patients (except of some early glottic tumor patients) were consecutively included in our IMRT program.

303/409 patients underwent definitive IMRT (dIMRT, $74 \%$ ), 106 were referred for postoperative IMRT (pIMRT, $26 \%)$. Tumor sites were oropharynx $(40 \%)$, oral cavity $(19 \%)$, hypopharynx (15\%), larynx (12\%), nasopharynx (10\%), and paranasal sinus $(2 \%)$. The mean/median follow up time was $23 / 20$ months (3-72). In $70 \%$ of all patients, $4-7$ cycles of simultaneous cisplatin $\left(40 \mathrm{mg} / \mathrm{m}^{2} / \mathrm{w}\right)$ were given, $9 \%$ tolerated 1-3 cycles. In $16 \%$, no chemotherapy was added, mainly due to co-morbidity or age. In 22 patients (5\%), concomitant

Table 1. Demographic information and clinical-pathological characteristics of the assessed cohort $(n=409)$. IMRT: intensity modulated radiotherapy; SCC: squamous cell carcinoma; CDDP: cisplatin; tGTV: total gross tumor volume; NA: not assessable; FU: follow-up.

Tabelle 1. Demographische Informationen und klinisch pathologische Charakteristika der untersuchten Kohorte $(n=409)$. IMRT: intensitätsmodulierte Radiotherpie; SCC: Plattenepithelkarzinom; CDDP: Cisplatin; tGTV: Gesamttumorvolumen; NA: nicht vorliegend; FU: Follow-up.

\begin{tabular}{|c|c|c|}
\hline Parameters & Definitive IMRT & Postoperative IMRT \\
\hline $\mathrm{N}$ & $303(74 \%)$ & $106(26 \%)$ \\
\hline $\begin{array}{l}\text { Gender }(m: f) \\
\text { Mean age (range) }\end{array}$ & $\begin{array}{l}236: 67 \\
60(21-87)\end{array}$ & $\begin{array}{l}84: 22 \\
60(32-85)\end{array}$ \\
\hline \multicolumn{3}{|l|}{ Diagnoses } \\
\hline Oropharynx & 125 & 39 \\
\hline Oral cavity & 34 & 45 \\
\hline Hypopharynx & 57 & 6 \\
\hline Larynx & 41 & 7 \\
\hline Nasopharynx & 39 & 0 \\
\hline Sinonasal & 5 & 4 \\
\hline Unkown SCC primary & 1 & 5 \\
\hline \multicolumn{3}{|l|}{$T$ stages } \\
\hline $\mathrm{Tx}$ & $1(3 \%)$ & $5(5 \%)$ \\
\hline $\mathrm{T} 1$ & $23(7 \%)$ & $24(22 \%)$ \\
\hline T2 & $97(32 \%)$ & $31(29 \%)$ \\
\hline T3 & $61(20 \%)$ & $7(7 \%)$ \\
\hline T4 & $98(32 \%)$ & $17(16 \%)$ \\
\hline Recurrence & $23(8 \%)$ & $22(21 \%)$ \\
\hline \multicolumn{3}{|l|}{$\mathrm{N}$ stages } \\
\hline NO & $49(16 \%)$ & $21(20 \%)$ \\
\hline N1 & $40(13 \%)$ & $11(10 \%)$ \\
\hline $\mathrm{N} 2 \mathrm{a} / \mathrm{b}$ & $85(28 \%)$ & $48(45 \%)$ \\
\hline $\mathrm{N} 2 \mathrm{c}$ & $98(32 \%)$ & $11(10 \%)$ \\
\hline N3 & $16(5 \%)$ & $6(5 \%)$ \\
\hline Recurrence & $15(5 \%)$ & $9(8 \%)$ \\
\hline \multicolumn{3}{|c|}{ Concomitant chemotherapy } \\
\hline None & $43(14 \%)$ & $23(22 \%)$ \\
\hline $1-3$ cycles CDDP & $28(9 \%)$ & $7(7 \%)$ \\
\hline 4-7 cycles CDDP & $216(71 \%)$ & $70(66 \%)$ \\
\hline Cetuximab & $16(5 \%)$ & $6(5 \%)$ \\
\hline tGTV & 57 & NA \\
\hline $16-70 \mathrm{cc}$ & 173 & NA \\
\hline$>70 \mathrm{cc}$ & 73 & NA \\
\hline Mean FU (range, mo.) & $22.6(3-72)$ & $20.1(3-64)$ \\
\hline
\end{tabular}




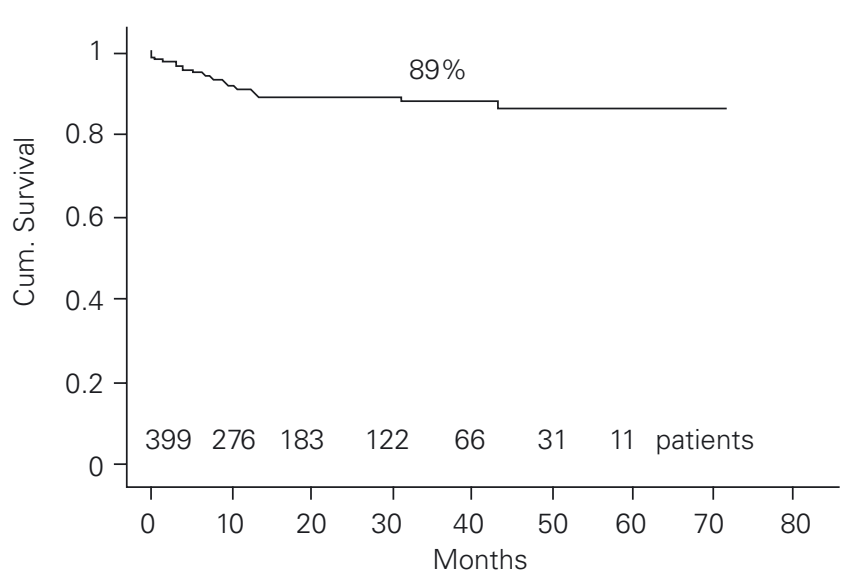

Figure 1.3-year distant control rate in 409 patients with intensity modulated radiation therapy (IMRT).

Abbildung 1. Metastasenfreies 3-Jahres-Überleben bei 409 Patienten mit intensitätsmodulierter Radiotherapie (IMRT).

cetuximab was given instead of cisplatin. All but 2 NPC patients underwent 1-3 cycles of cisplatin/5-fluorouracil (5-FU) 3-6 weeks following concomitant cisplatin-IMRT.

\section{Methods}

In a former evaluation, based on 88 retrospectively and 84 prospectively analysed patients (treated 01/2002-12/2004 and $01-11 / 2005 ; n$ total $=172$, in this recent study included), a volumetric staging system (VSS) was found the most important predictor of local-regional outcome [28]. This VSS bases on two cut-offs: primary or total gross tumor volume (GTV): 1-15 cc (favourable) vs. $16-70$ cc (intermediate) vs. $>70$ cc (unfavourable). While the primary GTV was used to predict local control rates, the total GTV was shown to best predict nodal control rates, disease free, and overall survival, respectively.

This volumetric criterion has since been applied prospectively in definitive IMRT patients (no GTV measurable in planning computed tomography [CT]) of operated patients), with respect to its predictive value for DM.

In addition, analyses taking the UICC (Union International Contre le Cancer) TNM criteria were performed, and the impact of treatment sequence, primary site, gender, and age as potential prognostic factors for DM, have been assessed. The recent study presents these results and its potential implications on clinical decisions.

All patients have been irradiated using IMRT with simultaneously integrated boost (SIB) technique [25], using dIMRT schedules with $33 \times 2.11$ Gy to the boost planning target volume (boost PTV), or, - as a mild dose escalation -, with $33 \times$ 2.2 Gy to large GTVs, or with $35 \times 2.0$ Gy to the boost PTV in patients with central nervous structures in the PTV, or with substantial parts of the larynx involved. The pIMRT schedule provided 30-33 × 2.0 Gy to the boost PTV. The elective dose
Table 2. Characteristics of distant metastasis (DM) patients. LF: local failure; NF: nodal failure. TU: tumor.

Tabelle 2. Charakteristika der Untergruppe mit Fernmetastasen (DM). LF: lokales Rezidiv; NF: nodale Metastasierung; TU:Tumor.

\begin{tabular}{lll}
\hline Parameters & $\mathbf{n}$ & $(\%)$ \\
\hline Distant Metastasis (DM) & $38 / 409$ & $(9)$ \\
DM only & $13 / 38$ & $(34)$ \\
DM + LF & $8 / 38$ & $(21)$ \\
DM + NF & $5 / 38$ & $(13)$ \\
DM + LF + NF & $12 / 38$ & $(26)$ \\
DM + 2nd TU & $4 / 38$ & $(11)$ \\
DM at initial diagnosis & $10 / 38$ & $(26)$ \\
DM sequence & & \\
DM together with LF/NF & $14 / 25$ & $(56)$ \\
DM > 6 months prior to LF/NF & $2 / 25$ & $(8)$ \\
DM > 6 months post LF/NF & $5 / 25$ & $(25)$ \\
\hline
\end{tabular}

was 54 Gy in most patients, intermediate doses of 60-66 Gy were delivered depending on individual risk.

All but 8 patients are in a regular follow up program in our HNC joint centre clinic or maxillofacial surgery clinic at the USZ. Routine tests included, besides the history, physical examination and endoscopy of the pharyngo-laryngeal region. If these tests were of no evidence of disease, usually no further tests were done but a CT scan or magnetic resonance imaging at 1 year post-treatment in the majority of patients.

\section{Statistics}

Survival data were calculated using Kaplan-Meier curves and log-rank tests implemented in StatView ${ }^{\circledR}$ (Version 4.5). Proportions were compared using the Chi-square test. $\mathrm{p}$ values $<0.05$ were considered statistically significant. Univariate and multivariate analyses were performed with a Cox proportional hazards regression model in StatView ${ }^{\circledR}$.

\section{Results}

3-year local and nodal control rates, disease free, and overall survival of the entire cohort were $80,87,73$, and $80 \%$, respectively. $74 \%$ of all patients were alive with no evidence of disease when last time seen.

A recent update of the definitive IMRT cohort using VSS shows 3-year local control rates of 93 vs. 78 vs. $50 \%$ for primary GTV 1-15 cc vs. 16-70 cc vs. $>70$ cc, respectively ( $<$ < $0.0001)$; the corresponding disease free survival rates are $82 \mathrm{vs.}$ 70 vs. $55 \%(p=0.0002)$, the overall survival rates are 88 vs. 75 vs. $65 \%(\mathrm{p}=0.13)$.

Distant metastasis (DM, Figure 1, Table 2) was diagnosed in 38 of all 409 patients (9\%); 10/38 presented with initial DM, resulting in a DM rate of $7 \%(28 / 399)$ in initially M0 patients. $15 / 38$ patients with DM died after mean/median 16/12 months (3-40) after completion of IMRT; mean/median survival time 
of still alive 23 patients at the time point of study analysis was $23 / 23$ months (4-47). The 2-year overall survival rate was $52 \%$ in patients with DM, $90 \%$ in DM free patients, respectively $(\mathrm{p}<0.0001) .6$ of 10 patients with DM at initial diagnosis died mean 21 months (4-40) after completion of IMRT, 4/10 were alive when last time seen, mean 14 months (4-42) after IMRT. In only $3 / 38$ patient, DM was diagnosed later than 12 months following completion of IMRT. Pre-treatment WHO performance status was 0 in 23, 1 in 15 of the 38 DM patients. The lung was the most frequent site of metastasis $(33 / 38,87 \%)$. In $13 / 28(46 \%)$ of metastasised initially M0 patients, DM remained the only manifestation of disease; 7 of these 13 died of



Figure 2. Distant control rate, analysed according to the total gross tumor volume (tGTV), measured in 303 patients with definitive intensity modulated radiation therapy (IMRT) (cut off values 15 and $70 \mathrm{cc}$ ).

Abbildung 2. Metastasenfreies Überleben, analysiert nach dem Gesamttumorvolumen (tGTV) bei 303 Patienten mit definitiver intensitätsmodulierter Radiotherapie (IMRT) (Schnittstellen: 15 und $70 \mathrm{cc}$ ).
DM mean/median 17 months (9-36) post-treatment, 6 are still alive, mean 18 months post-treatment (3-43). There were no characteristic features detectable in this 'DM only' subgroup, compared with local-regional failure DM patients.

\section{Predictive Factors for DM (Figure 2, Table 3)}

The pre-therapeutic GTV revealed to be the strongest predictive factor for DM in definitively irradiated patients with measurable primary or total GTV ( $\mathrm{p}<0.0001$ each, (Figure 2 ) out of all assessed potentially predictive parameters. Only 9/230 patients $(4 \%)$ with a total GTV $<70$ cc developed DM, vs. $18 / 73$ patients $(25 \%)$ with total GVT $>70 \mathrm{cc}$. In uni- and multivariate analysis, the $\mathrm{T}$ - and $\mathrm{N}$-systems were not significantly predicting the DM probability but in the constellation of localregionally advanced stages ( $\geq \mathrm{T} 3 \mathrm{~N} 2 \mathrm{~b}$ ) and $\mathrm{N} 0-1$ vs. $\mathrm{N}>1$ (Table 3). Treatment sequence was not related to the DM rate (11/106 postoperative [10\%] vs. 27/303 [9\%] definitive IMRT patients). The site of primary was not a statistically significant predictor. DM was found in $6 \%$ of hypopharynx, $7 \%$ of oropharynx, $8 \%$ of oral cavity, $10 \%$ of nasopharyngeal cancer (NPC), and $14 \%$ of laryngeal tumors, respectively. Separate analyses showed no difference to the non-NPC cohort with respect to the DM rate (4/39 NPC [10\%], 24/269 non-NPC [9\%]; 3-y distant control $86 \%$ each). Age was not a significant factor neither, with mean 60.7 vs. 60.5 years in the DM vs. distantly controlled group.

All but one distant event occurred in men, however, 26\% (61/236) of all male patients presented with a total GTV $>70$ cc (i.e. 'at risk' for DM), while this was the case in only $12 \%$ $(8 / 67)$ of females $(p=0.059$, Chi-square proportion test). A retrospective analysis of the impact of cisplatin on DM showed no difference between patients with no chemotherapy vs the ones with 1-3 vs. 4-7 cycles, however, this is of limited value,

Table 3. Potentially predictive parameters for distant metastasis (DM): p-values. 26 and $25 \%$ of patients with primary gross tumor volume (pGTV) or total GTV (tGTV) > $70 \mathrm{cc}$, respectively, developed DM. DC: without distant metastasis.

Tabelle 3. Potenzielle prädiktive Faktoren für Fernmetastasierung (DM): $p$-Werte. 26 und $25 \%$ der Patienten mit Primärtumorvolumen ( $p G T V$ ) oder Gesamttumorvolumen (tGTV) > 70 cc entwickelten DM. DC: frei von Fernmetastasen. .

\begin{tabular}{|c|c|c|c|c|}
\hline Parameters & $\mathrm{N}$ patients & $\mathrm{p}$ - value & DM $(\%)$ & 3y DC (\%) \\
\hline Tx sequence (postoperative vs. definitive IMRT) & & 0.98 & & \\
\hline Simultaneous Cisplatin (none vs. $1-3$ vs. $4-7$ cycles) & & 0.39 & & \\
\hline Diagnosis & & 0.29 & & \\
\hline $\mathrm{T}$ & & 0.36 & & \\
\hline T1,2 vs. T3,4, reccurence & & 0.19 & & \\
\hline T1-2 N0-2b vs. all others & & 0.25 & & \\
\hline $\mathrm{N}$ & & 0.23 & & \\
\hline N0-1 vs. > N1 & 122 / 261 & 0.04 & 5 vs. 12 & 93 vs. 88 \\
\hline$\geq T 3 N 2 b$ vs. all others & $127 / 276$ & 0.007 & 14 vs. 7 & 84 vs. 91 \\
\hline pGTV (1-15 cc vs. $16-70$ cc vs. $>70$ cc) & $104 / 150 / 40$ & $<0.0001$ & 6 vs. 6 vs. 26 & 92 vs. 92 vs. 67 \\
\hline tGTV (1-15 cc vs. $16-70$ cc vs. > 70 cc) & $57 / 173 / 73$ & $<0.0001$ & 2 vs. 7 vs. 25 & 98 vs. 95 vs. 67 \\
\hline tGTV $<70 \mathrm{cc} /$ anyN vs. tGTV $>70 \mathrm{cc}+\geq \mathrm{N} 2 \mathrm{~b}$ & $223 / 59$ & $<0.0001$ & 4 vs. 23 & 95 vs. 70 \\
\hline tGTV $<70 \mathrm{cc} /$ anyN vs. tGTV $>70 \mathrm{cc}+<\mathrm{N} 2 \mathrm{~b}$ & $223 / 15$ & $<0.0001$ & 4 vs. .20 & 95 vs. 70 \\
\hline
\end{tabular}


as the subgroup with no or few cycles of cisplatin is characterized by elderly or co-morbid patients.

$14 \%$ of patients $(59 / 409)$ were diagnosed for a second or even third or forth primary prior or following IMRT, 4 of them belonged to the DM subgroup.

\section{Discussion}

The observed low DM incidence rate of 7\% (28/399 patients with initial M0-status, (Figure 1) is concordant with that of recent reports in the IMRT literature, ranging between 8-12\% (>90\% 3y DM-free survival) $[4,6,19,30]$ following IMRT-chemotherapy, and seems to be lower than many published values following conventional radiation techniques, with $\sim 8-25 \%$ of $\mathrm{DM}[1,2,3,8,11,14,24]$. A relation between increasing localregional tumor control rates following IMRT and this tendency to decreasing DM rates can not be excluded.

Associations between various factors like primary site, regional extension ( $\mathrm{TN}$-stage), grading and others, and the rate of DM have been reported [2, 12, 15, 20, 23, 24, 30].

In our cohort, GTV was the strongest statistically significant predictor for DM (Table 3). Tumor volume has formerly been reported as a statistically significant factor for DM in HNC by Chao et al. [4] (as well as for other tumors [29]). As far as we know, the here presented study is the first attempt to use a VSS with defined predictive cut off values for DM prediction. The tested VSS has been reported as a highly reliable tool to predict local-regional outcome [28], and could herewith been confirmed as similarly reliable in predicting DM (Figure 2).

Our N0-1 vs. N > 1 nodal subgroups showed a less strong but significant difference in predicting DM $(p=0.04)$, while $\mathrm{N}$-status itself was not significant (yet), likely due to the small number of events per $\mathrm{N}$-stage, and maybe also due to the fact that not all lymph nodes considered as 'tumor affected' have been histopathologically confirmed. Even if the difference was statistically significant, the percentage difference of DM was low (5 vs. $12 \%$, (Table 3 ), and therefore this criterion not too helpful as prognostic selection tool. Similarly, the combination of advanced TN stages resulted in a ratio of only $14 \%$ vs. $7 \%$ DM. The 'risky' constellation 'tGTV > 70 cc plus advanced $\mathrm{N}$ status $\geq \mathrm{N} 2 \mathrm{~b}$ ' revealed to be equal to the constellation 'tGTV > $70 \mathrm{cc}$ plus early N status < N2b', compared to 'tGTV < 70 cc plus any N' (23 and 20 vs. $4 \%$ DM), showing the superiority of the volumetric over the nodal criterion ( $\mathrm{Ta}$ ble 3, grey field).

The site of the primary may influence the rate of DM, with reported $~ 75-$ $80 \%$ 2-3y DM-free survival rates in localregionally advanced nasopharyngeal $[16$, 18, 21, 29], sinonasal [9, 13, 22], hypopha- ryngeal [27] and laryngeal tumors [5], 85-95\% in oropharyngeal tumors $[4,7,15]$, and $~ 90-95 \%$ in oral cavity cancer (OCC) [3-6, 10], respectively. For local-regionally advanced hypopharyngeal tumors, $3 y$-DM free survival rates of as low as $30 \%$ are reported $[8,17]$. Comparisons of DM rates between the studies are difficult due to a wide range of treatment approaches, staging examinations, and treatments. In our population, no significant primary site related difference was found, likely due to imbalanced samples with low numbers of events per entity; with respect to the equal DM rate in NPC and non-NPC, one has to consider the different treatment, with additional post-radiochemotherapeutic chemotherapy (cisplatin/5-FU) in NPC, according to the standard.

All but one patient with DM were men. However, considering that $62 / 236$ dIMRT treated male patients presented with a tumor volume $>70 \mathrm{cc}(26 \%)$, while this was the case in only $8 / 67$ women ( $12 \%$, i.e. 2-times less large tumors in women), this has to be taken with caution.

\section{Potential Consequences of Volumetric DM Prediction}

One quarter of patients with GTV > 70 cc presented with DM at diagnosis or during the first 12 months from treatment start, while only $4 \%$ with GTV $<70 \mathrm{cc}$. Volumetric staging may serve as selection tool to detect high risk patients for DM with respect to the question of IC. In some randomised earlier trials, adjuvant chemotherapy in patients with locally advanced HNC showed a reduction of DM from $\sim 25-15 \%$, a relative reduction of approximately $40 \%$. We consider this observation as helpful information in discussing IC.

For various subgroups at risk, the number needed to treat (NNT) has been calculated (Table 4): the NNT was lowest for the volumetric criterion (factor 1.5 to $\sim 3$ ), the absolute number of patients who may profit from IC is small.

Table 4. Induction chemotherapy (IC): number needed to treat (NNT) in various subgroups at risk. tGTV: total gross tumor volume (in 303 patients with definitive intensity modulated radiotherapy). DM: distant metastatsis.

Tabelle 4. Induktionschemotherapie: „number needed to treat“ (NNT) für diverse Risikogruppen. tGTV: Gesamttumorvolumen (bei 303 Patienten mit definitiver intensitätsmodulierter Radiotherapie). DM: Fernmetastasen.

\begin{tabular}{|c|c|c|c|c|}
\hline Subgroups at risk & $\begin{array}{l}\text { n/N Patients } \\
(\%)\end{array}$ & $\begin{array}{l}\text { n Distant failure } \\
(\%)\end{array}$ & $\begin{array}{l}\text { Absolute reduction (\%) } \\
\text { of DM (based on } 40 \% \\
\text { relative risk reduction) }\end{array}$ & NNT \\
\hline $\mathrm{T} 3 / 4$ or recurrence & $\begin{array}{l}219 / 399 \\
(55)\end{array}$ & $\begin{array}{l}16 \\
(7)\end{array}$ & $7.3-4.4$ & 34 \\
\hline$>\mathrm{N} 2 \mathrm{a}$ or recurrence & $\begin{array}{l}260 / 399 \\
(65)\end{array}$ & $\begin{array}{l}23 \\
(9)\end{array}$ & $8.8-5.3$ & 29 \\
\hline $\mathrm{T} 3 / 4 \mathrm{~N} 2 \mathrm{~b}-3$ or recurrence & $\begin{array}{l}120 / 399 \\
(30)\end{array}$ & $\begin{array}{l}13 \\
(11)\end{array}$ & $10.8-6.5$ & 23 \\
\hline $\mathrm{tGTV}>70 \mathrm{cc}$ & $\begin{array}{l}68 / 295 \\
(23)\end{array}$ & $\begin{array}{l}13 \\
(19)\end{array}$ & $19.1-11.5$ & 13 \\
\hline All & $\begin{array}{l}399 / 399 \\
(100)\end{array}$ & $\begin{array}{l}28 \\
(7)\end{array}$ & $7.0-4.2$ & 36 \\
\hline
\end{tabular}


There is still a certain probability that IC could also be loco-regionally effective, however, hardly by a similar factor than concomitant radio-chemotherapy is.

With respect to pre-therapeutic M-staging with PET(CT), VSS would similarly allow to narrow DM search to a subgroup of high risk for DM. Considering that findings of 'small/limited/suspected' DM at diagnosis do often not change our localregional treatment approach (i.e., patients with initially diagnosed limited DM and local-regionally disease considered as 'curable', underwent IMRT with 'local-regionally curative' intention), one could even provide to confine M-staging to the few patients with local-regionally as 'hardly curable' stated disease, in order to use PETCT to ease the decision for palliative treatment.

VSS may therefore translate into therapeutic and/or diagnostic consequences.

\section{Conclusion}

GTV was the most significant predictor for DM, revealing DM in one quarter of patients with GTV $>70 \mathrm{cc}$ vs. $<5 \%$ in patients with GTV $<70 \mathrm{cc}$, respectively. These finding could translate into a more rationale and selective pre-treatment $\mathrm{M}$ staging, and consideration of induction chemotherapy confined to patients at high risk. These are the same patients who could benefit from an improvement of local-regional control. However, even in the DM high risk group, the subgroup with isolated DM, that could benefit from IC, is small.

\section{References}

1. Adelstein DJ, Leblanc M. Does induction chemotherapy have a role in the management of locoregionally advanced squamous cell head and neck cancer? J Clin Oncol 2006;24:2624-8.

2. Alvi A, Johnson JT. Development of distant metastasis after treatment of advanced-stage head and neck cancer. Head Neck 1997;19:500-5.

3. Bonner JA, Harari PM, Giralt J, et al. Radiotherapy plus cetuximab for squamous-cell carcinoma of the head and neck. N Engl J Med 2006;354:567-78.

4. Chao KS, Ozyigit G, Blanco AI, et al. Intensity-modulated radiation therapy for oropharyngeal carcinoma: impact of tumor volume. Int J Radiat Oncol Biol Phys 2004;59:43-50.

5. Cmelak AJ, Li S, Goldwasser MA, et al. Phase II trial of chemoradiation for organ preservation in resectable stage III or IV squamous cell carcinomas of the larynx or oropharynx: results of Eastern Cooperative Oncology Group Study E2399. J Clin Oncol 2007;25:3971-7.

6. Daly ME, Lieskovsky Y, Pawlicki T, et al. Evaluation of patterns of failure and subjective salivary function in patients treated with intensity modulated radiotherapy for head and neck squamous cell carcinoma. Head Neck 2007:29:211-20.

7. de Arruda FF, Puri DR, Zhung J, et al. Intensity-modulated radiation therapy for the treatment of oropharyngeal carcinoma: the Memorial Sloan-Kettering Cancer Center experience. Int J Radiat Oncol Biol Phys 2006;64:363-73.

8. Dietl B, Marienhagen J, Schaefer C, et al. [Frequency and distribution pattern of distant metastases in patients with ENT tumors and their consequences for pretherapeutic staging]. Strahlenther Onkol 2007;183:138-43.

9. Dirix $P$, Nuyts $S$, Geussens $Y$, et al. Malignancies of the nasal cavity and paranasal sinuses: long-term outcome with conventional or three-dimensional conformal radiotherapy. Int J Radiat Oncol Biol Phys 2007;69:1042-50.

10. Eich HT, Loschcke M, Scheer M, et al. Neoadjuvant radiochemotherapy and radical resection for advanced squamous cell carcinoma of the oral cavity. Outcome of 134 patients. Strahlenther Onkol 2008;184:23-9.

11. Garden AS, Harris J, Vokes EE, et al. Preliminary results of Radiation Therapy Oncology Group 97-03: a randomized phase ii trial of concurrent radia- tion and chemotherapy for advanced squamous cell carcinomas of the head and neck. J Clin Oncol 2004;22:2856-64.

12. Hoeller U, Biertz I, Flinzberg S, et al. Hyperfractionated-accelerated radiotherapy followed by radical surgery in locally advanced tumors of the oral cavity. Strahlenther Onkol 2006;182:157-63.

13. Hoppe BS, Stegman LD, Zelefsky MJ, et al. Treatment of nasal cavity and paranasal sinus cancer with modern radiotherapy techniques in the postoperative setting-the MSKCC experience. Int J Radiat Oncol Biol Phys 2007;67:691-702.

14. Huguenin $\mathrm{P}$, Beer KT, Allal $\mathrm{A}$, et al. Concomitant cisplatin significantly improves locoregional control in advanced head and neck cancers treated with hyperfractionated radiotherapy. J Clin Oncol 2004;22:4665-73.

15. Kowalski LP, Carvalho AL, Martins Priante AV, et al. Predictive factors for distant metastasis from oral and oropharyngeal squamous cell carcinoma. Oral Oncol 2005;41:534-41.

16. Lee AW, Tung SY, Chan AT, et al. Preliminary results of a randomized study (NPC-9902 Trial) on therapeutic gain by concurrent chemotherapy and/or accelerated fractionation for locally advanced nasopharyngeal carcinoma. Int J Radiat Oncol Biol Phys 2006;66:142-51.

17. Lee MS, Ho HC, Hsiao SH, et al. Treatment results and prognostic factors in locally advanced hypopharyngeal cancer. Acta Otolaryngol 2007;1-7.

18. Lee N, Xia P, Quivey JM, et al. Intensity-modulated radiotherapy in the treatment of nasopharyngeal carcinoma: an update of the UCSF experience. Int J Radiat Oncol Biol Phys 2002;53:12-22.

19. Lee NY, O'Meara W, Chan K, et al. Concurrent chemotherapy and intensitymodulated radiotherapy for locoregionally advanced laryngeal and hypopharyngeal cancers. Int J Radiat Oncol Biol Phys 2007;69:459-68.

20. Leibel SA, Scott CB, Mohiuddin M, et al. The effect of local-regional control on distant metastatic dissemination in carcinoma of the head and neck: results of an analysis from the RTOG head and neck database. Int J Radiat Oncol Biol Phys 1991;21:549-56.

21. Lu H, Yao M. The current status of intensity-modulated radiation therapy in the treatment of nasopharyngeal carcinoma. Cancer Treat Rev 2008;34:27-36.

22. Shingaki S, Suzuki I, Kobayashi T, et al. Predicting factors for distant metastases in head and neck carcinomas: an analysis of 103 patients with locoregional control. J Oral Maxillofac Surg 1996;54:853-7.

23. Shingaki S, Takada M, Sasai K, et al. Impact of lymph node metastasis on the pattern of failure and survival in oral carcinomas. Am J Surg 2003; 185:278-84.

24. Spector GJ. Distant metastases from laryngeal and hypopharyngeal cancer. ORL J Otorhinolaryngol Relat Spec 2001;63:224-8.

25. Studer G, Huguenin PU, Davis JB, et al. IMRT using simultaneously integrated boost (SIB) in head and neck cancer patients. Radiat Oncol 2006;1:7.

26. Studer G, Luetolf UM, Glanzmann C. Locoregional failure analysis in headand-neck cancer patients treated with IMRT. Strahlenther Onkol 2007;183: 417-23; discussion 424-5.

27. Studer G, Lutolf UM, Davis JB, et al. IMRT in hypopharyngeal tumors. Strahlenther Onkol 2006;182:331-5.

28. Studer G, Lutolf UM, El-Bassiouni M, et al. Volumetric staging (VS) is superior to TNM and AJCC staging in predicting outcome of head and neck cancer treated with IMRT. Acta Oncol 2007;46:386-94.

29. Ullmann C, Beck JD, Holter W, et al. [Long-term results following multidisciplinary treatment of localized Ewing's sarcoma in children and adolescents]. Strahlenther Onkol 2008;184:137-44.

30. Yao M, Nguyen T, Buatti JM, et al. Changing failure patterns in oropharyngeal squamous cell carcinoma treated with intensity modulated radiotherapy and implications for future research. Am J Clin Oncol 2006;29:606-12.

\author{
Address for Correspondence \\ Gabriela Studer, MD \\ Radiation Oncology \\ University Hospital Zurich (USZ) \\ Rämistrasse 100 \\ 8091 Zurich \\ Switzerland \\ Fax (+41/44) 2554547 \\ e-mail:gabriela.studer@usz.ch
}

